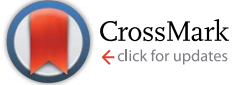

Cite this: RSC Adv., 2017, 7, 7560

Received 2nd December 2016 Accepted 17th January 2017

DOI: $10.1039 / c 6 r a 27678 d$

www.rsc.org/advances

\section{Cascade catalysis via dehydration and oxidation: one-pot synthesis of 2,5-diformylfuran from fructose using acid and $\mathrm{V}_{2} \mathrm{O}_{5}$ /ceramic catalysts $\dagger$}

\begin{abstract}
Mei Cui, ${ }^{a}$ Renliang Huang, ${ }^{* b}$ Wei Qi, ${ }^{\text {acd }}$ Rongxin $\mathrm{Su}^{\text {acd }}$ and Zhimin $\mathrm{He}^{\mathrm{a}}$
2,5-Diformylfuran (2,5-DFF) is an important biomass chemical with broad application prospects. A vanadium pentoxide $\left(\mathrm{V}_{2} \mathrm{O}_{5}\right)$ /ceramic powder catalyst $(\mathrm{V}-\mathrm{CP})$ was designed and synthesized in this study, and its structure was characterized by scanning electron microscopy (SEM), X-ray diffraction (XRD), X-ray photoelectron spectroscopy (XPS), and specific surface area analysis (BET). The catalytic properties of the $\mathrm{V}$-CP catalyst were evaluated. The results show that 5-hydroxymethylfurfural (5-HMF) can be completely converted to 2,5 -DFF at $140{ }^{\circ} \mathrm{C}$ under atmospheric pressure in the presence of oxygen as the oxidant in dimethyl sulfoxide (DMSO) for $5 \mathrm{~h}$, and the yield of 2,5-DFF was $85.7 \%$. After recycling the catalyst 5 times, the catalytic effect decreased slightly, and the catalyst showed good recovery performance. Furthermore, a one-pot method for the preparation of 2,5-DFF was proposed by using fructose as the raw material and $\mathrm{V}_{2} \mathrm{O}_{5}$ /ceramic-dilute sulfuric acid as the catalyst. The fructose was dehydrated to form $5-\mathrm{HMF}$, and 2,5-DFF was generated by the V-CP catalytic oxidation of 5-HMF. The 2,5-DFF yield was $68.4 \%$. The results of this study provide a valuable reference for the efficient one-pot synthesis of biomass-based furan chemicals.
\end{abstract}

\section{Introduction}

With the reduction of fossil resources and deterioration of the global environment, the development of biomass-based liquid fuels and high-value chemicals has become the focus of academic and industrial concerns. Among them, the chemical furan has become an important platform compound, ${ }^{\mathbf{1 - 5}}$ including 5-hydroxymethylfurfural (5-HMF), ${ }^{6-11}$ 2,5-diformylfuran (2,5-DFF), ${ }^{12-15}$ 2,5-furandicarboxylic acid (FDCA), ${ }^{16-20}$ 2,5-dimethylfuran (DMF), ${ }^{21,22}$ etc. These compounds can be prepared by the dehydration, oxidation, or reduction of glucose and fructose generated from the hydrolysis of biomass. There are two aldehyde groups in the 2,5-DFF, which make the chemical very active. Therefore, a variety of useful compounds and polymer materials, such as plastics, fuels, and additives,

${ }^{a}$ State Key Laboratory of Chemical Engineering, School of Chemical Engineering and Technology, Tianjin University, Tianjin 300072, China. E-mail: qiwei@tju.edu.cn; Fax: +86 22 27407599; Tel: +86 2227407799

${ }^{b}$ Tianjin Engineering Center of Bio Gas/Oil Technology, School of Environmental Science and Engineering, Tianjin University, Tianjin 300072, China. E-mail: tjuhrl@ tju.edu.cn

'Collaborative Innovation Center of Chemical Science and Engineering (Tianjin), Tianjin 300072, China

${ }^{d}$ Tianjin Key Laboratory of Membrane Science and Desalination Technology, Tianjin University, Tianjin 300072, China

$\dagger$ Electronic supplementary information (ESI) available: Supplementary figures. See DOI: $10.1039 / \mathrm{c} 6 \mathrm{ra} 27678 \mathrm{~d}$ can be synthesized through the hydrogenation, oxidation, polymerization, and hydrolysis of $2,5-\mathrm{DFF} .^{23-25}$

Generally, 2,5-DFF can be prepared by the catalytic oxidation of 5-HMF. The main types of catalysts are noble metals, manganese-based catalysts, vanadium-based catalysts, and polymetallic catalysts. For noble metals, Zhu et al. ${ }^{26}$ used $\mathrm{MnO}_{2}$ microspheres as the carrier for Au catalyst, achieving a 5-HMF conversion of $82 \%$ and a $2,5-\mathrm{DFF}$ selectivity of $99 \%$ using DMF as the solvent. In addition, Nie et al. ${ }^{27}$ used different carriers for $\mathrm{Ru}$ in the catalytic oxidation of 5-HMF. The results showed that when active carbon was used, the yield of 2,5-DFF can be as high as $96 \%$ in toluene at $110{ }^{\circ} \mathrm{C}$ and $2.0 \mathrm{MPa}$ of $\mathrm{O}_{2}$. For manganesebased catalysts, Nie et al. ${ }^{28}$ investigated the effect of the existence of different forms of manganese on the catalytic oxidation of 5-HMF, and using manganese oxide octahedral molecular sieve (OMS-2) as the catalyst and DMF as the solvent after $1 \mathrm{~h}$ at $110{ }^{\circ} \mathrm{C}$ under $0.5 \mathrm{MPa}_{2}$, a 5-HMF to 2,5-DFF conversion of $100 \%$ and a selectivity of $97.2 \%$ were achieved. Furthermore, Yadav $^{29}$ et al. synthesized a composite catalyst Ag-OMS-2 (silver content of $15 \%$ ). This catalyst was used in isopropanol at $165^{\circ} \mathrm{C}$ under an air pressure of 1.52 MPa for $4 \mathrm{~h}$, giving a 5-HMF to 2,5DFF conversion of $99 \%$ and a selectivity of $100 \%$.

Moreover, vanadium-based catalysts are also used in the catalytic oxidation of 5-HMF for the preparation of 2,5-DFF due to their superior catalytic performance and low cost. In homogeneous catalysis, $\mathrm{Ma}$ et al. $^{\mathbf{2 4}}$ investigated the homogeneous oxidation of 5-HMF in acetonitrile using $\mathrm{VOSO}_{4}$ and $\mathrm{Cu}\left(\mathrm{NO}_{3}\right)_{2}$ as catalysts. It provided a 5 -HMF to $2,5-\mathrm{DFF}$ conversion of $99 \%$ 
and a selectivity of $99 \%$. In heterogeneous catalysis, Sádaba et al. ${ }^{30}$ prepared a vanadium pentoxide $\left(\mathrm{V}_{2} \mathrm{O}_{5}\right) /$ zeolite catalyst for 2,5-DFF preparation, and an $83.2 \%$ yield was achieved in dimethylformamide. Antonyraj et $a .^{31}$ used a $\mathrm{V}_{2} \mathrm{O}_{5} /$ active carbon catalyst for the selective oxidation of 5-HMF to $2,5-\mathrm{DFF}$, which provided a conversion of $95 \%$ and a selectivity of $96 \%$ after $4 \mathrm{~h}$ of reaction under $0.28 \mathrm{MPa}$ of oxygen in methyl isobutyl ketone. Overall, high yields and selectivities for 2,5-DFF production were obtained in some studies, specially with high pressure of $\mathrm{O}_{2}$.

In recent years, some researchers have tried to synthesize 2,5-DFF directly from fructose or glucose. Fructose can be directly dehydrated to prepare 5-HMF, and therefore, the preparation of 2,5-DFF using fructose as raw material has been extensively studied. ${ }^{32-34}$ For example, Yang et al. ${ }^{32}$ used $\mathrm{Fe}_{3} \mathrm{O}_{4}-$ $\mathrm{SBA}-\mathrm{SO}_{3} \mathrm{H}$ for the catalyzed dehydration of fructose to prepare 5 -HMF, followed by K-OMS-2 catalytic oxidation of 5-HMF to prepare 2,5-DFF. That study used a two-step method for the preparation of 2,5-DFF from fructose and generated a 2,5-DFF yield of $80 \%$. Liu et al. ${ }^{33}$ synthesized a new type of molybdenumbased polyoxometalates that has dual catalytic functions of dehydration and oxidation and converted fructose to $2,5-\mathrm{DFF}$ using a one-pot method. The 2,5-DFF yield reached $69.3 \%$ under the optimum conditions. In the research of glucose as raw material, Takagaki et $a .^{35}$ studied the preparation of 2,5DFF from glucose and fructose using cation exchange resin (Amberlyst-15) and ruthenium-hydrotalcite $(\mathrm{Ru} / \mathrm{HT})$ as catalysts, generating 2,5-DFF yields of $25 \%$ and $49 \%$, respectively. Xiang et al. ${ }^{36}$ used $\mathrm{CrCl}_{3} / \mathrm{NaBr}$ and vanadate $\mathrm{NaVO}_{3}$ as the composite catalysts to prepare 2,5-DFF from glucose using a one-pot two-step method, with a 2,5 -DFF yield of $55 \%$. In general, the product yield and selectivity using catalysts with dual functionality or multiple catalysts for 2,5-DFF preparation directly from fructose or glucose, still need further improvement, and difficulty also exists in the reuse of multiple catalysts in the two-step process.

Ceramic is one of the ideal carriers for industrial catalytic reactions due to its excellent physical properties, such as a high melting point, high hardness, and high wear resistance as well as its excellent mechanical properties. ${ }^{37}$ It also has the advantages of corrosion resistance to acid and alkali, oxidation resistance, easy preparation, low cost, etc. Therefore, ceramics have been chosen as the catalyst matrix/carrier by many researchers. ${ }^{38,39}$ Previously, our group had synthesized various ceramic used as enzyme carriers, which exhibited good catalytic performance. ${ }^{38-40}$ In addition, our group has been committed to the synthesis of biomass-based furan chemicals, especially 5-HMF synthesis, regarding which much work has been carried out. ${ }^{\mathbf{8 1 1 , 1 4 , 4 1}}$ The heterogeneous catalyst, which was prepared by doping ceramics with metal or metal oxide, has the catalytic properties of metal elements while retaining the advantages of ceramics. It should be an excellent catalyst for the synthesis of furan chemicals.

In this paper, a new $\mathrm{V}_{2} \mathrm{O}_{5}$ /ceramic catalyst (V-CP) was prepared by co-sintering catalytic active $\mathrm{V}_{2} \mathrm{O}_{5}$ with a ceramic matrix component. The chemical composition and microstructure of the catalyst were systematically characterized by scanning electron microscopy (SEM), X-ray diffraction (XRD), X-

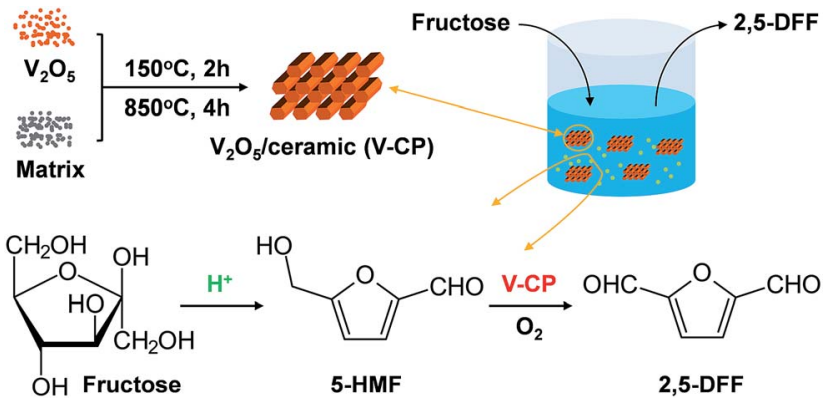

Scheme 1 Preparation of $\mathrm{V}_{2} \mathrm{O}_{5}$ /ceramic catalysis and one-pot synthesis of 2,5-DFF from fructose.

ray photoelectron spectroscopy (XPS), and specific surface area analysis (BET). 2,5-DFF was prepared from 5-HMF using V-CP as a catalyst and $\mathrm{O}_{2}$ as an oxidizing atmosphere under normal pressure. The effects of the reaction temperature, reaction time, $\mathrm{V}_{2} \mathrm{O}_{5}$ content, and solvent on the catalytic performance were investigated, and the recovery performance of V-CP was also evaluated. Furthermore, a one-pot method for the synthesis of 2,5-DFF from fructose was developed using V-CP and dilute sulfuric acid as the catalyst under normal pressure (Scheme 1). The changes in the contents of fructose, 5-HMF, and 2,5-DFF in the reaction system were analyzed by high performance liquid chromatography (HPLC).

\section{Experimental}

\subsection{Materials and reagents}

5-HMF (>99\%), 2,5-DFF (>99\%), and fructose (>99\%) were obtained from the Sigma-Aldrich (Beijing, China). Dimethyl sulfoxide (DMSO, >99.8\%) was purchase from the Concord Technology Co. Ltd. (Tianjing, China). $\mathrm{V}_{2} \mathrm{O}_{5}$ (>98\%), sodium silicate $\left(\mathrm{Na}_{2} \mathrm{SiO}_{3},>98 \%\right)$, magnesium oxide (MgO, >98\%), calcium oxide $(\mathrm{CaO},>98 \%)$, silicon dioxide $\left(\mathrm{SiO}_{2},>95 \%\right)$, aluminum oxide $\left(\mathrm{Al}_{2} \mathrm{O}_{3},>98 \%\right)$, and concentrated sulfuric acid were purchased from the Guangfu Institute of Fine Chemicals (Tianjin, China).

\subsection{Preparation of the $\mathrm{V}_{2} \mathrm{O}_{5} /$ ceramic catalyst}

$\mathrm{SiO}_{2}, \mathrm{Al}_{2} \mathrm{O}_{3}, \mathrm{Na}_{2} \mathrm{SiO}_{3}, \mathrm{~V}_{2} \mathrm{O}_{5}, \mathrm{MgO}, \mathrm{CaO}$, and water were mixed in a mass ratio of $10: 5: 5: 2.6: 1: 1: 1$. The mixture was then dried at $150{ }^{\circ} \mathrm{C}$ for $2 \mathrm{~h}$. The temperature was increased at a heating rate of $4{ }^{\circ} \mathrm{C} \mathrm{min}^{-1}$, and the mixture was calcinated at $850{ }^{\circ} \mathrm{C}$ for $4 \mathrm{~h}$. After cooling down to room temperature and soaking in a $3 \%$ sulfuric acid solution for $2 \mathrm{~h}$, the catalyst was washed and dried to obtain the V-CP with $10 \mathrm{wt} \%$ of $\mathrm{V}_{2} \mathrm{O}_{5}$.

To compare and examine the effect of the catalyst composition on the properties of the catalysts, ceramic catalysts with the $\mathrm{V}_{2} \mathrm{O}_{5}$ contents of 0 (ceramic matrix, CP), $1 \%, 5 \%, 15 \%$, and $20 \%$ were prepared using the same process as described above.

\subsection{Characterization of catalysts}

$\mathrm{X}$-ray diffraction (XRD, D/MAX-2500, scanning range from 10$90^{\circ}$ at a scanning speed of $6^{\circ} \mathrm{min}^{-1}$, Rigaku, Japan) was used to 
characterize the structure of blank ceramic matrix (CP) and VCP. Scanning electron microscopy (SEM, S4800, Hitachi, Japan) images of the catalysts were acquired with an accelerating voltage of $5 \mathrm{kV}$ to examine their morphologies. The specific surface area of the catalyst was measured using a BET nitrogen adsorption apparatus (F-sorp 2400, Beijing Jin Aipu Technology Co. Ltd.). The elemental composition and chemical valance on the surface of the catalyst were analyzed by X-ray photoelectron spectroscopy (XPS, PHI-5000 Versa Probe, ULVAC-PHI, Japan).

\subsection{Catalytic performance test}

2.4.1 Preparation of 2,5-DFF by the catalytic oxidation of 5HMF. Four milliliters (mL) of DMSO, $63 \mathrm{mg}$ of 5-HMF, and $100 \mathrm{mg}$ of V-CP were added to the reaction vessel and placed in an oil bath at a set temperature. The reaction was initiated by

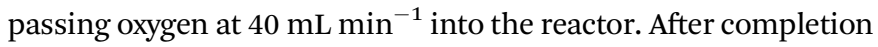
of the reaction, the catalyst was collected by centrifugation and washed three times using water. The reaction solution and washing solution were collected, and the volume was adjusted to $50 \mathrm{~mL}$. The product was analyzed using high-performance liquid chromatography (HPLC). The effects of the solvent composition, reaction temperature, reaction time, flow rate of $\mathrm{O}_{2}$, and $\mathrm{V}_{2} \mathrm{O}_{5}$ loading amount on the conversion and yield were investigated.

2.4.2 Preparation of 2,5-DFF by the one-pot catalytic conversion of fructose

Route $1.4 \mathrm{~mL}$ of DMSO, $90 \mathrm{mg}$ of fructose, $11 \mu \mathrm{L}$ of concentrated sulfuric acid, and $100 \mathrm{mg}$ of $\mathrm{V}-\mathrm{CP}$ (10 wt\%) were added to the reaction vessel, which was placed in an oil bath at $140{ }^{\circ} \mathrm{C}$ to initiate a dehydration reaction. After $20 \mathrm{~min}$, the oxidation reaction was conducted by passing oxygen at $40 \mathrm{~mL} \min ^{-1}$ into the reactor. After completion of the reaction, the catalyst was collected by centrifugation and washed three times using water. The reaction solution and washing solution were collected, and the volume was adjusted to $50 \mathrm{~mL}$. The product was analyzed using HPLC.

Route 2. $4 \mathrm{~mL}$ of DMSO, $90 \mathrm{mg}$ of fructose, and $11 \mu \mathrm{L}$ of concentrated sulfuric acid were added to the reaction vessel, which was placed in an oil bath at $140{ }^{\circ} \mathrm{C}$ to start the dehydration reaction. After $20 \mathrm{~min}, 100 \mathrm{mg}$ of $\mathrm{V}-\mathrm{CP}$ (10 wt\%) was added to the vessel, and the oxidation reaction was initiated by

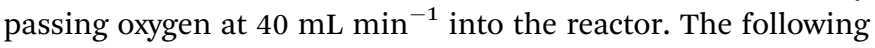
process was the same as in route 1.

2.4.3 Analytical approaches. The concentrations of fructose, 5-HMF, and 2,5-DFF were measured using HPLC (Agilent, USA) equipped with an a refractive index (RI) detector. An HPX$87 \mathrm{H}$ ion exclusion column $(300 \times 7.8 \mathrm{~mm}$, Bio-Rad Co. USA $)$ was used with a column oven temperature of $65^{\circ} \mathrm{C}$, a mobile phase of $0.005 \mathrm{M} \mathrm{H}_{2} \mathrm{SO}_{4}$ at a flow rate of $0.7 \mathrm{~mL} \mathrm{~min}^{-1}$, and an injection volume of $100 \mu \mathrm{L}$. All samples were filtered through a $0.22 \mu \mathrm{m}$ membrane prior to injection.

\section{Results and discussion}

\subsection{Characterization of the catalyst structure}

The morphologies of the ceramic matrix (CP) and $\mathrm{V}_{2} \mathrm{O}_{5} /$ ceramic catalyst (V-CP) were observed by scanning electron microscopy
(SEM), as shown in Fig. 1. SEM images showed that the CP and V-CP morphologies were similar. A large number of hexagonal prisms can be clearly seen. In addition, there were some amorphous components attached to the surfaces of the hexagonal prisms.

XRD was used to verify the crystal structures of CP and V-CP. Fig. 2 shows that both CP and V-CP have obvious diffraction peaks, and particularly, there is a strong absorption peak at $27^{\circ}$. Analysis using MDI Jade software showed that the XRD patterns of the two were very close, and the characteristic peaks of $\mathrm{SiO}_{2}$ hexagonal crystals exist. These results indicated that the basic lattice structure of the ceramic was retained after the incorporation of $\mathrm{V}_{2} \mathrm{O}_{5}$. The peak intensities of $\mathrm{MgO}$ and $\mathrm{CaO}$ decreased after the incorporation of $\mathrm{V}_{2} \mathrm{O}_{5}$ due to their content decrease. However, $\mathrm{SiO}_{2}$ and $\mathrm{Al}_{2} \mathrm{O}_{3}$, as the main constituents of ceramic, still exhibit very high diffraction peak intensities in the V-CP pattern. This is consistent with other ceramic catalysts synthesized in our laboratory. ${ }^{39}$ In addition, the diffraction peaks of $\mathrm{V}_{2} \mathrm{O}_{5}$ were not detected in the XRD pattern of $\mathrm{V}-\mathrm{CP}$, which indicated that $\mathrm{V}_{2} \mathrm{O}_{5}$ existed mainly in an amorphous form.

The XPS spectra of the $\mathrm{V}_{2} \mathrm{O}_{5}$ /ceramic catalysts and the relative atomic ratios, as well as the binding energies of the major elements, are shown in Fig. 3 and Table 1. The results showed that the binding energies of the major elements, $\mathrm{Si}, \mathrm{Al}, \mathrm{Mg}, \mathrm{Ca}$, and $\mathrm{Na}$, in $\mathrm{CP}$ and $\mathrm{V}$-CP are basically the same, which indicated that each element has the same chemical valence in $\mathrm{CP}$ and VCP. From Fig. 3 b, it can be seen that there are characteristic peaks at $517.7 \mathrm{eV}$ and $524.2 \mathrm{eV}$ corresponding to $\mathrm{V} 2 \mathrm{p}_{3 / 2}$ and $\mathrm{V}^{2} \mathrm{p}_{1 / 2}$ orbitals, respectively, which indicates that the vanadium exists as +5 in $\mathrm{V}_{2} \mathrm{O}_{5}$. This is consistent with the XPS spectra results from Antonyraj et al., ${ }^{31}$ who used active carbon as
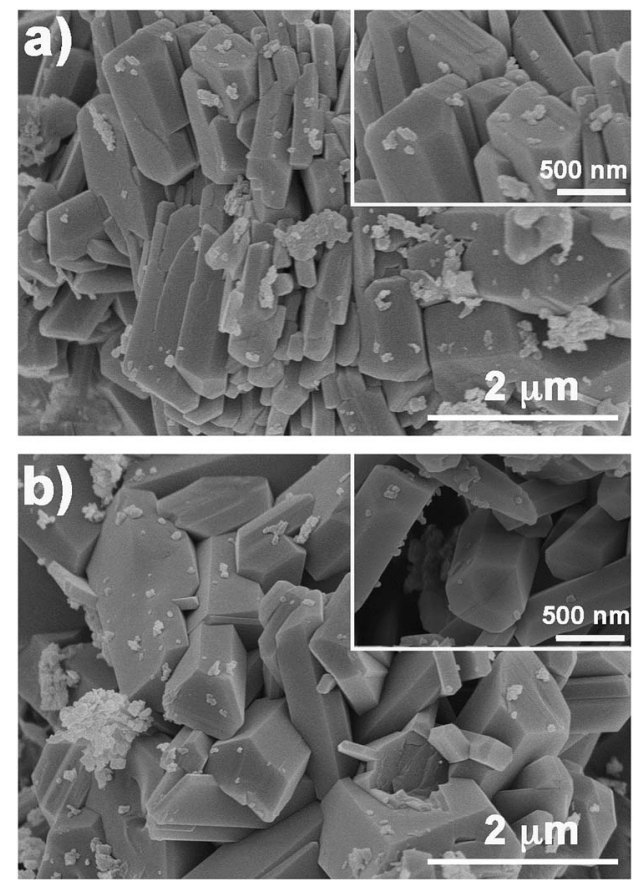

Fig. 1 SEM images of (a) ceramic matrix (CP) and (b) $\mathrm{V}_{2} \mathrm{O}_{5}$ /ceramic catalyst. 

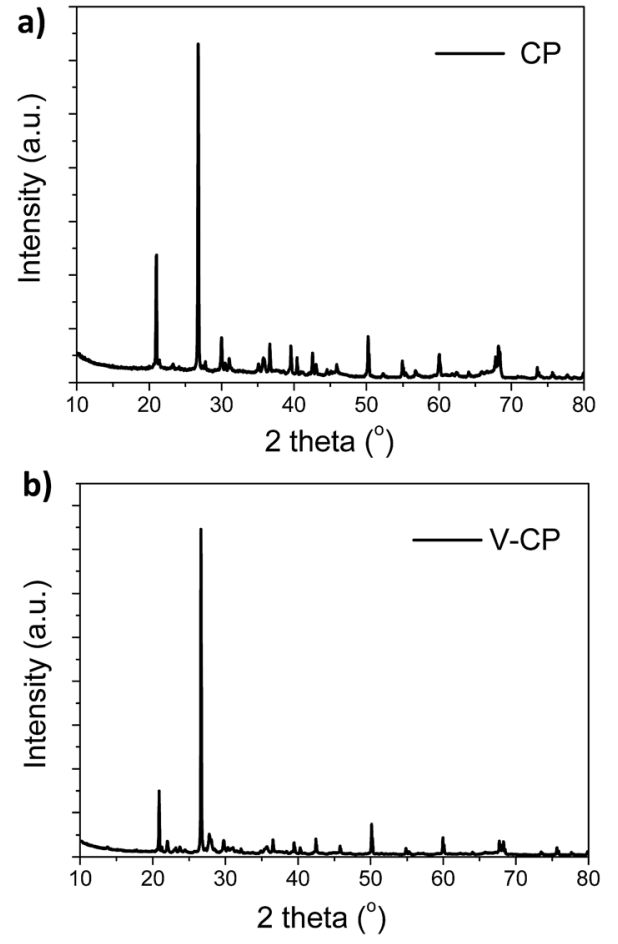

Fig. 2 XRD patterns of $C P$ and $V-C P$.
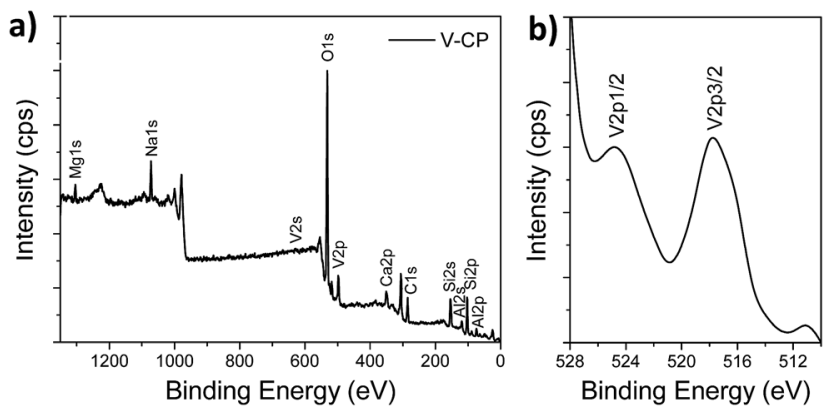

Fig. 3 XPS spectra for $\mathrm{V}-\mathrm{CP}$.

a carrier for $\mathrm{V}_{2} \mathrm{O}_{5}$, and Adil et al. ${ }^{42}$ who used a nickel manganese oxide as a carrier for $\mathrm{V}_{2} \mathrm{O}_{5}$ to prepare the catalyst.

In addition, the BET specific surface areas of the blank ceramic matrix and $\mathrm{V}_{2} \mathrm{O}_{5}$ /ceramic catalyst were also measured. The results showed that the BET specific surface area of CP is $10.8 \mathrm{~m}^{2} \mathrm{~g}^{-1}$ and that of V-CP is $17.9 \mathrm{~m}^{2} \mathrm{~g}^{-1}$. Both materials have very small specific surface areas, which is determined by the ceramic preparation process (including the temperature, heating rate, and not using a pore-forming agent). Under these conditions, the surface fluidity of the base material is significant, which results in the planarization of CP and V-CP surfaces. SEM images also showed no obvious pores for both CP and V$\mathrm{CP}$, which is consistent with the BET results.

\subsection{Preparation of 2,5-DFF by the catalytic oxidation of 5- HMF using V-CP}

2,5-DFF was prepared by the catalytic oxidation of 5-HMF using $\mathrm{O}_{2}$ as the oxidant for the catalytic performance evaluation of $\mathrm{V}_{2} \mathrm{O}_{5} /$ ceramic catalysts. The effects of the reaction temperature, time, $\mathrm{V}_{2} \mathrm{O}_{5}$ content, and solvent composition on the 5-HMF conversion and 2,5-DFF yield were systematically investigated, as shown in Fig. 4. The 2,5-DFF selectivity is $85.7-95.3 \%$ when the temperature is in the range of $100-140{ }^{\circ} \mathrm{C}$, which indicates that the V-CP has high selectivity, especially under the lower temperature. However, only a small amount of 5-HMF $(<23 \%)$ was converted to 2,5-DFF after $5 \mathrm{~h}$ of reaction at temperatures below $120^{\circ} \mathrm{C}$ (Fig. 4a), which may due to the low reaction rate at low temperature. The conversion of 5-HMF and yield of 2,5-DFF gradually increased as the temperature increased. The 5-HMF conversion was $100 \%$ and the 2,5 -DFF yield was $85.7 \%$ at $140{ }^{\circ} \mathrm{C}$ after $5 \mathrm{~h}$ of reaction. The selectivity gradually decreased (from $95.3 \%$ to $85.7 \%$ ) with the increase of the temperature, which is likely due to formation of by-products. The HPLC results show that the main by-products are levulinic acid (LA), formic acid (FA) and 2,5-furandicarboxylic acid (FDCA). At $140{ }^{\circ} \mathrm{C}$ and $5 \mathrm{~h}$, the yield of LA, FA and FDCA is $5.7 \%, 4.5 \%$ and $3.4 \%$, respectively. In this case, the conversion of $5-\mathrm{HMF}$ is $100 \%$ and the total yield of 2,5-DFF and by-products is $99.4 \%$. Compared with other catalysts (see ESI Table S1 $\dagger$ ), the yield of 2,5-DFF in this paper is higher or comparable, but the value is lower than those of other homogeneous catalytic systems (e.g., $\mathrm{VOSO}_{4} / \mathrm{Cu}\left(\mathrm{NO}_{3}\right)_{2}$, ESI Table S1†).

At $140{ }^{\circ} \mathrm{C}$, the conversion of 5-HMF to 2,5-DFF versus time is shown in Fig. $4 \mathrm{~b}$. The conversion of 5-HMF and yield of 2,5-DFF increased rapidly in the first three hours, and then, the change in the trend became slow, reaching $100 \%$ and $87.5 \%$, respectively, at $5 \mathrm{~h}$. The selectivity of 2,5-DFF decreased as the reaction progresses, which is due to the gradually formed by-products as the reaction proceeds. For example, the generated 2,5-DFF can be further oxidized and generate FDCA.

Fig. 4c shows the effects of different $\mathrm{V}_{2} \mathrm{O}_{5}$ loadings on the conversion of 5-HMF and yield of 2,5-DFF. With the $\mathrm{V}_{2} \mathrm{O}_{5}$ loading increasing from $1 \%$ to $10 \%$, the conversion of $5-\mathrm{HMF}$ (from $4.8 \%$ to $100 \%$ ) and the yield of 2,5 -DFF (from $4.3 \%$ to $85.7 \%$ ) both increased dramatically at $140{ }^{\circ} \mathrm{C}$ and $5 \mathrm{~h}$ of

Table 1 Relative atomic ratios and binding energies of the main elements in $\mathrm{CP}$ and $\mathrm{V}-\mathrm{CP}$

\begin{tabular}{|c|c|c|c|c|c|c|c|c|c|c|}
\hline $\mathrm{CP}$ & atm\% & 13.8 & 52.6 & 4.7 & 2.6 & 8.8 & 15.1 & 2.3 & - & - \\
\hline & Binding energy (eV) & 284.8 & 531.5 & 1071.9 & 49.7 & 74.2 & 102.4 & 347.1 & - & - \\
\hline
\end{tabular}



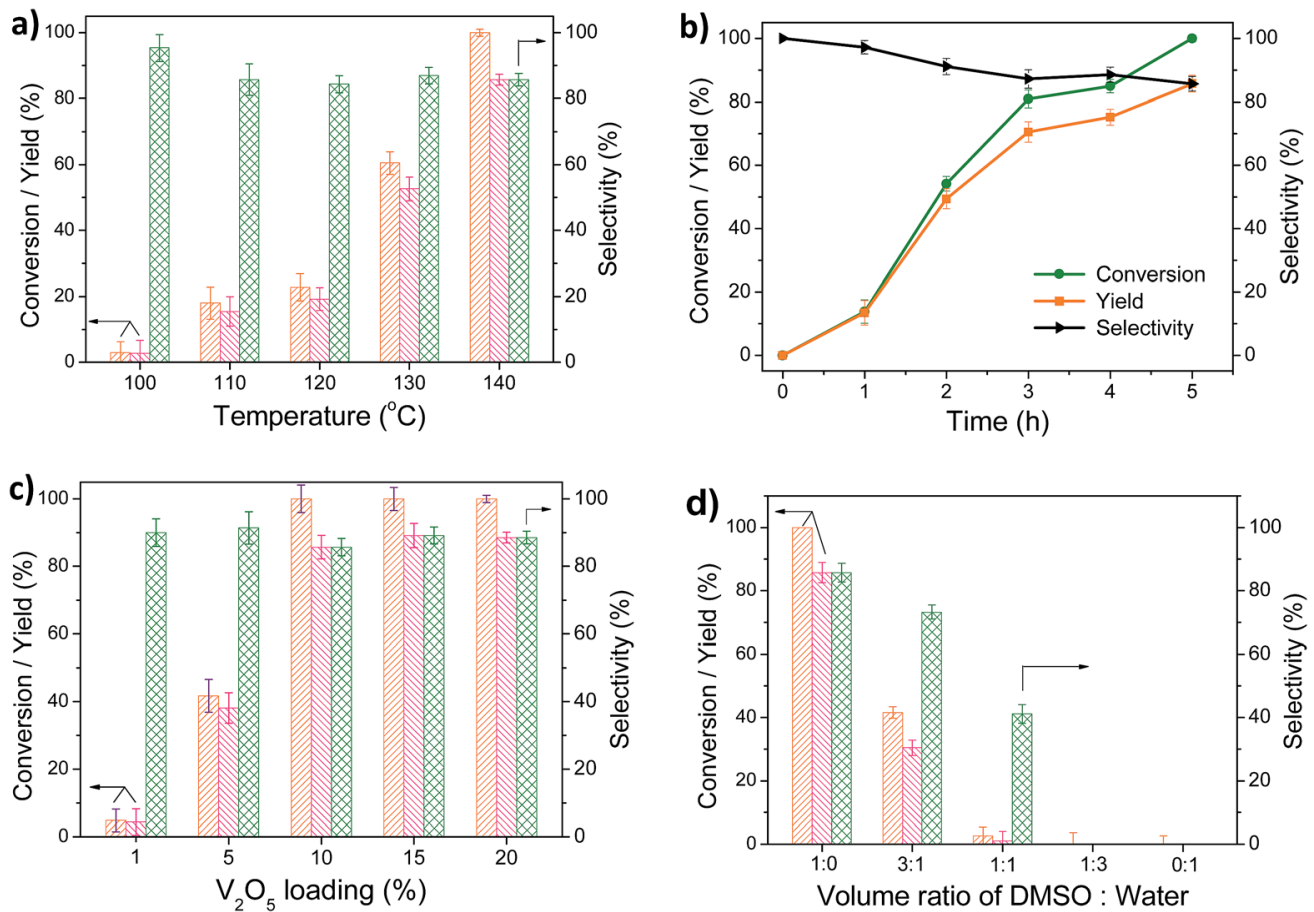

Fig. 4 The effects of different reaction conditions on the preparation of 2,5-DFF by the catalytic oxidation of 5-HMF using V-CP ((a) reaction temperature, (b) time, (c) $\mathrm{V}_{2} \mathrm{O}_{5}$ content, and (d) DMSO/water volume ratio). If not specified, the default reaction conditions were as follows: 5 $\mathrm{HMF}, 63 \mathrm{mg} ; \mathrm{V}-\mathrm{CP}, 100 \mathrm{mg} ; \mathrm{V}_{2} \mathrm{O}_{5}$ content, $10 \%$; solvent, $\mathrm{DMSO}$; volume, $4 \mathrm{~mL} ; \mathrm{O}_{2}, 40 \mathrm{~mL} \mathrm{~min}^{-1}$; temperature, $140{ }^{\circ} \mathrm{C}$; and reaction time, $5 \mathrm{~h}$.

reaction, with an insignificant change in the 2,5-DFF yield. A further increase in the $\mathrm{V}_{2} \mathrm{O}_{5}$ loading to $15 \%$ also increased the 2,5-DFF yield and selectivity slightly. However, the 2,5-DFF yield and selectivity decreased slightly when the $\mathrm{V}_{2} \mathrm{O}_{5}$ loading increased to $20 \%$, which indicated that the higher content of $\mathrm{V}_{2} \mathrm{O}_{5}$ also promoted side reactions.

We investigated the effect of the flow rate of $\mathrm{O}_{2}$ on 2,5-DFF synthesis. As shown in Fig. S1, $\uparrow$ with increasing the flow rate of

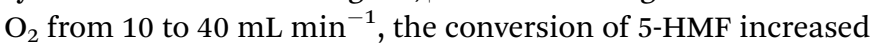
from $69.7 \%$ to $100 \%$ and the yield of $2,5-\mathrm{DFF}$ increased form $57.9 \%$ to $85.7 \%$. A further increase in the oxygen flow rate to 60 $\mathrm{mL} \min ^{-1}$, there is no significant change in the 2,5-DFF yield.

Moreover, the effects of different solvents on the efficiency of the catalytic reaction were also investigated in this paper. Fig. 4d shows that the conversion of 5-HMF and the yield/ selectivity of 2,5-DFF were the highest in DMSO solvent, which indicated that DMSO can effectively inhibit the occurrence of side reactions and promote 2,5-DFF formation. Water is the greenest solvent for liquid phase reactions. In this paper, different volume ratios of DMSO- $\mathrm{H}_{2} \mathrm{O}$ mixed solutions were used as solvents, and the results showed that the 5-HMF conversion and 2,5-DFF yield decreased significantly with an increase in the water content. No oxidation of 5-HMF occurred and no 2,5-DFF was formed in pure water and $\mathrm{DMSO} / \mathrm{H}_{2} \mathrm{O} 1: 3$ systems. Additionally, we also investigated the effect of the different organic solvents (acetonitrile, tetrahydrofuran, dimethylformamide) on the 2,5-DFF production. The results show that yield of 2,5 -DFF is lower than $10 \%$ in these cases, which indicated that the DMSO has a significant effect on the preparation of 2,5-DFF by 5 -HMF oxidation.
To evaluate the recovery performance of $\mathrm{V}-\mathrm{CP}$, the reaction solution was filtered and washed with double distilled water three times after the first reaction. The dried V-CP was then subjected to 5-HMF oxidation under the same conditions, and the results are shown in Fig. 5. After being recycled five times, the 5-HMF conversion decreased gradually from $100 \%$ to $94 \%$, and the 2,5-DFF yield decreased from $85.7 \%$ to $70.6 \%$ at $140{ }^{\circ} \mathrm{C}$ and $5 \mathrm{~h}$ of reaction. In the recovery process, the filtration, transfer, and other experimental operations resulted in the loss of $\mathrm{V}$-CP, while the active ingredient $\mathrm{V}_{2} \mathrm{O}_{5}$ in the catalyst may also have leaked slowly. Therefore, the 2,5-DFF yield and selectivity both decreased slightly. Overall, this catalyst showed good recovery performance.

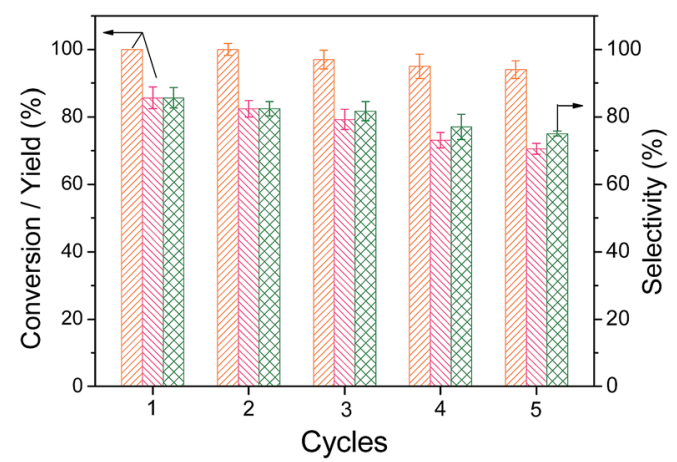

Fig. 5 Recycling and reuse of $\mathrm{V}$-CP for 2,5-DFF production. Reaction conditions: $5-\mathrm{HMF}, 63 \mathrm{mg} ; \mathrm{V}-\mathrm{CP}, 100 \mathrm{mg} ; \mathrm{V}_{2} \mathrm{O}_{5}$ content, 10\%; DMSO,

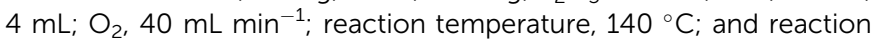
time, $5 \mathrm{~h}$. 


\subsection{Preparation of 2,5-DFF by the one-pot catalytic conversion of fructose}

Fructose is a sustainable biomass raw material. Research has shown that 5-HMF can be prepared by acid-catalyzed dehydration using fructose. In this paper, fructose was used as the raw material to prepare 2,5-DFF by a one-pot method with diluted sulfuric acid and $\mathrm{V}_{2} \mathrm{O}_{5}$ /ceramic catalysts to catalyze the dehydration of fructose and oxidation of 5-HMF. In the experiment, two experimental procedures were used to carry out the reaction according to the time of addition of the $\mathrm{V}_{2} \mathrm{O}_{5}$ /ceramic catalyst.

The first one included adding V-CP together with the diluted sulfuric acid into the reaction system. The oxygen was introduced after $20 \mathrm{~min}$ of dehydration for oxidation. Fig. 6a shows that the 5-HMF yield increased from 0 to $67.2 \%$ in the first 10 min of reaction with the rapid conversion of fructose. However, the yield decreased to $59.0 \%$ after further reaction until $20 \mathrm{~min}$. The 2,5-DFF yield increased gradually from 0 to $21.8 \%$ after the introduction of oxygen, while the 5-HMF yield decreased to $16.4 \%$ due to its oxidation reaction.

The second approach included adding diluted sulfuric acid first and then adding the V-CP catalyst with oxygen for oxidation after 20 min of dehydration. Fig. 6b shows that the yield of 5HMF reached $76.6 \%$ at 20 min of reaction time with the rapid conversion of fructose. After adding $\mathrm{V}-\mathrm{CP}$ and introducing oxygen, 5-HMF was converted, and the 2,5-DFF yield increased
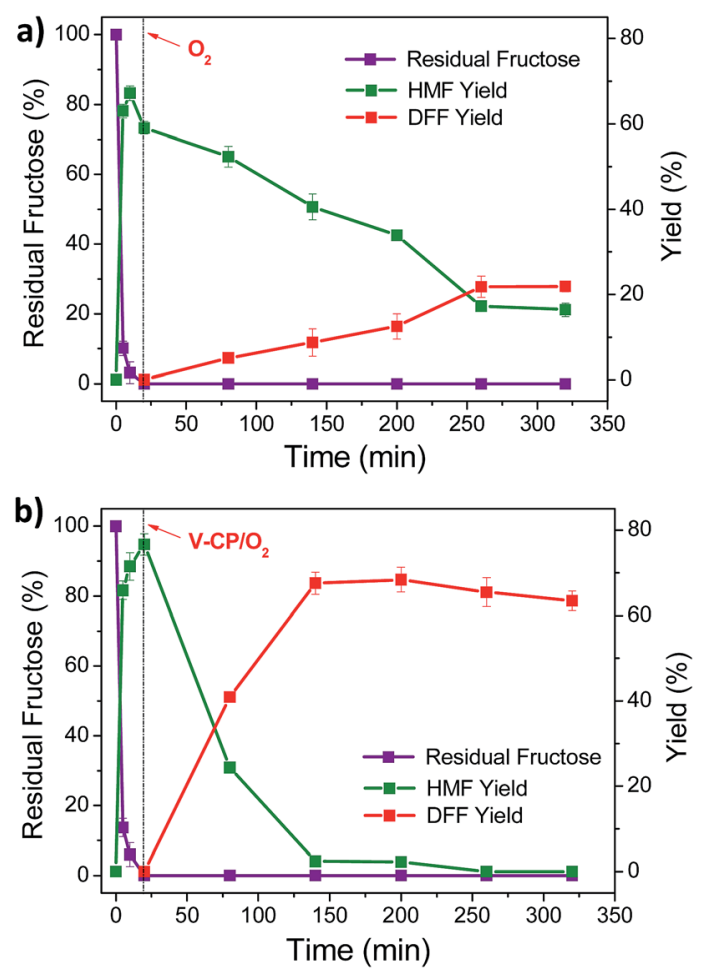

Fig. 6 Reaction curve of 2,5-DFF preparation by the one-pot $\mathrm{V}_{2} \mathrm{O}_{5} /$ ceramic and diluted sulfuric acid co-catalysis method. (a) Adding V-CP at the beginning of the reaction together with acid and introducing oxygen after 20 min of reaction time. (b) Adding V-CP and oxygen after $20 \mathrm{~min}$ of reaction time. Reaction conditions: fructose, $90 \mathrm{mg}$; acid

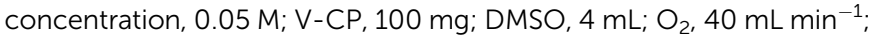
and reaction temperature, $140{ }^{\circ} \mathrm{C}$. to $67.6 \%$ rapidly from $20 \mathrm{~min}$ to $140 \mathrm{~min}$. The $2,5-\mathrm{DFF}$ yield reached the maximum of $68.4 \%$ after $200 \mathrm{~min}$. Compared with another catalytic system (see ESI Table S2 $\dagger$ ), the yield of the $\mathrm{H}_{2} \mathrm{SO}_{4} / \mathrm{V}$-CP system in this paper is higher or comparable. For example, in the case of molybdenum-based polyoxometalates $\left(\mathrm{Cs}_{0.5} \mathrm{H}_{2.5} \mathrm{PMo}_{12}\right),{ }^{33}$ the yield of 2,5 -DFF is $69.3 \%$ at $433 \mathrm{~K}$ using air as oxidant. Formic acid and levulinic acid were detected as the main by-products; for $\mathrm{V}-\mathrm{g}-\mathrm{C}_{3} \mathrm{~N}_{4}\left(\mathrm{H}^{+}\right) / \mathrm{V}-\mathrm{g}-\mathrm{C}_{3} \mathrm{~N}_{4},{ }^{43}$ the dehydration reaction was conducted under $\mathrm{N}_{2}(0.1 \mathrm{MPa})$ at $120^{\circ} \mathrm{C}$ for $2 \mathrm{~h}$ and then the $\mathrm{V}-\mathrm{g}-\mathrm{C}_{3} \mathrm{~N}_{4}$ was added under $\mathrm{O}_{2}(0.1 \mathrm{MPa})$ at $130{ }^{\circ} \mathrm{C}$ for $6 \mathrm{~h}$, achieving the highest yield of $63 \%$; for $\mathrm{Fe}_{3} \mathrm{O}_{4}-$ SBA-SO ${ }_{3} \mathrm{H} / \mathrm{K}-\mathrm{OMS}-2{ }^{32}$ the 2,5 -DFF yield was up to $80 \%$ by stepwise addition of catalysts. However, the coexistence of these two catalyst in the initial stage of reaction resulted in low 2,5DFF yield, which is probably due to the formation of humins or the oxidation of fructose. In this study, further reactions resulted in slightly lower yields of 2,5-DFF, which was mainly due to the further reaction of 2,5-DFF.

The above experimental results showed that the second procedure is obviously superior to the first, as higher fructose conversion and 2,5-DFF yield were obtained. When V-CP and acid catalysts were added into the system at the same time, V-CP can possibly catalyze the undesired oxidation of fructose, which resulted in the lower yield of 5-HMF using the first method compared to the second one (67.2\% vs. $76.6 \%)$. In addition, due to the lack of oxygen atmosphere in the system, the generated 5HMF cannot be rapidly oxidized to 2,5-DFF, which may also generate some by-products (e.g., humins). These by-products inhibited the catalytic activity of $\mathrm{V}-\mathrm{CP}$ and resulted in a lower yield of 2,5-DFF in the first method than in the second $(21.8 \%$ vs. $68.4 \%)$.

\section{Conclusions}

A new $\mathrm{V}_{2} \mathrm{O}_{5}$ /ceramic catalyst was synthesized and successfully applied to the efficient catalytic oxidation of 5-HMF to 2,5-DFF. The results of structural characterization showed that the doping of $\mathrm{V}_{2} \mathrm{O}_{5}$ did not change the crystal structure of the ceramic, and $\mathrm{V}_{2} \mathrm{O}_{5}$ sintered on the surface of the ceramic crystal in the amorphous form. 2,5-DFF was prepared by catalyzing 5$\mathrm{HMF}$ at $140{ }^{\circ} \mathrm{C}$ under atmospheric pressure in the presence of oxygen as the oxidant in DMSO, and the yield of 2,5-DFF was $85.7 \%$. After 5 times of recycling this catalyst, the 2,5-DFF yield was still over $70 \%$, which showed good recovery performance. Furthermore, a new one-pot method for the preparation of 2,5DFF from fructose was proposed by using fructose as the raw material and $\mathrm{V}_{2} \mathrm{O}_{5}$ /ceramic-dilute sulfuric acid as the catalyst. The conversion of fructose was $100 \%$, and the 2,5 -DFF yield was $68.4 \%$. The catalyst and catalytic process proposed in this paper provide a new method for the efficient synthesis of 2,5-DFF from fructose.

\section{Acknowledgements}

This work was supported by the Natural Science Foundation of Tianjin, China (No. 16JCYBJC19600), the Natural Science 
Foundation of China (No. 21621004) and the Beiyang Young Scholar of Tianjin University (2012).

\section{References}

1 A. A. Rosatella, S. P. Simeonov, R. F. M. Frade and C. A. M. Afonso, Green Chem., 2011, 13, 754-793.

2 J. P. Lange, E. van der Heide, J. van Buijtenen and R. Price, ChemSusChem, 2012, 5, 150-166.

3 T. Wang, M. W. Nolte and B. H. Shanks, Green Chem., 2014, 16, 548-572.

4 J. Song, H. Fan, J. Ma and B. Han, Green Chem., 2013, 15, 2619-2635.

5 X. Liu, J. Xiao, H. Ding, W. Zhong, Q. Xu, S. Su and D. Yin, Chem. Eng. J., 2016, 283, 1315-1321.

6 J. B. Binder and R. T. Raines, J. Am. Chem. Soc., 2009, 131, 1979-1985.

7 G. Yong, Y. Zhang and J. Y. Ying, Angew. Chem., Int. Ed., 2008, 47, 9345-9348.

8 R. Huang, W. Qi, R. Su and Z. He, Chem. Commun., 2010, 46, 1115-1117.

9 A. Chinnappan, C. Baskar and H. Kim, RSC Adv., 2016, 6, 63991-64002.

10 Z. M. Xue, M. G. Ma, Z. H. Li and T. C. Mu, $R S C$ Adv., 2016, 6, 98874-98892.

11 Z. Yang, W. Qi, R. Huang, J. Fang, R. Su and Z. He, Chem. Eng. J., 2016, 296, 209-216.

12 R. Fang, R. Luque and Y. Li, Green Chem., 2016, 18, 31523157.

13 S. Wang, Z. Zhang, B. Liu and J. Li, Ind. Eng. Chem. Res., 2014, 53, 5820-5827.

14 Y. Wang, B. Liu, K. Huang and Z. Zhang, Ind. Eng. Chem. Res., 2014, 53, 1313-1319.

15 L. F. Liao, Y. Liu, Z. Y. Li, J. P. Zhuang, Y. B. Zhou and S. Z. Chen, RSC Adv., 2016, 6, 94976-94988.

16 X. Wan, C. Zhou, J. Chen, W. Deng, Q. Zhang, Y. Yang and Y. Wang, ACS Catal., 2014, 4, 2175-2185.

17 H. Ait Rass, N. Essayem and M. Besson, ChemSusChem, 2015, 8, 1206-1217.

18 Z. Zhang, J. Zhen, B. Liu, K. Lv and K. Deng, Green Chem., 2015, 17, 1308-1317.

19 L. Gao, K. Deng, J. Zheng, B. Liu and Z. Zhang, Chem. Eng. J., 2015, 270, 444-449.

20 Y. W. Zhang, Z. M. Xue, J. F. Wang, X. H. Zhao, Y. H. Deng, W. C. Zhao and T. C. Mu, RSC Adv., 2016, 6, 51229-51237.
21 Y. Roman-Leshkov, C. J. Barrett, Z. Y. Liu and J. A. Dumesic, Nature, 2007, 447, 982-985.

22 X. Xiang, J. Cui, G. Ding, H. Zheng, Y. Zhu and Y. Li, ACS Sustainable Chem. Eng., 2016, 4, 4506-4510.

23 A. Gandini, Green Chem., 2011, 13, 1061-1083.

24 J. Ma, Z. Du, J. Xu, Q. Chu and Y. Pang, ChemSusChem, 2011, 4, 51-54.

25 A. Gandini and M. N. Belgacem, Prog. Polym. Sci., 1997, 22, 1203-1379.

26 Y. Zhu, M. Shen, Y. Xia and M. Lu, Catal. Commun., 2015, 64, 37-43.

27 J. Nie, J. Xie and H. Liu, J. Catal., 2013, 301, 83-91.

28 J. Nie and H. Liu, J. Catal., 2014, 316, 57-66.

29 G. D. Yadav and R. V. Sharma, Appl. Catal., B, 2014, 147, 293301.

30 I. Sádaba, Y. Y. Gorbanev, S. Kegnæs, S. S. R. Putluru, R. W. Berg and A. Riisager, ChemCatChem, 2013, 5, 284-293.

31 C. A. Antonyraj, B. Kim, Y. Kim, S. Shin, K.-Y. Lee, I. Kim and J. K. Cho, Catal. Commun., 2014, 57, 64-68.

32 Z. Z. Yang, J. Deng, T. Pan, Q. X. Guo and Y. Fu, Green Chem., 2012, 14, 2986-2989.

33 Y. Liu, L. Zhu, J. Tang, M. Liu, R. Cheng and C. Hu, ChemSusChem, 2014, 7, 3541-3547.

34 Z. Yang, W. Qi, R. Su and Z. He, Energy Fuels, 2017, 31, 533541.

35 A. Takagaki, M. Takahashi, S. Nishimura and K. Ebitani, ACS Catal., 2011, 1, 1562-1565.

36 X. Xiang, L. He, Y. Yang, B. Guo, D. Tong and C. Hu, Catal. Lett., 2011, 141, 735-741.

37 K. Onitsuka, A. Dogan, J. F. Tressler, Q. Xu, S. Yoshikawa and R. E. Newnham, J. Intell. Mater. Syst. Struct., 1995, 6, 447455.

38 Z. Wu, W. Qi, M. Wang, R. Su and Z. He, J. Mol. Catal. B: Enzym., 2014, 110, 32-38.

39 Z. Wu, W. Qi, M. Wang, Y. Wang, R. Su and Z. He, Biochem. Eng. J., 2013, 77, 190-197.

40 Y. Qu, Z. Wu, R. Huang, W. Qi, R. Su and Z. He, RSC Adv., 2016, 6, 64581-64588.

41 N. Jiang, R. Huang, W. Qi, R. Su and Z. He, BioEnergy Res., 2012, 5, 380-386.

42 S. F. Adil, S. Alabbad, M. Kuniyil, M. Khan, A. Alwarthan, N. Mohri, W. Tremel, M. N. Tahir and M. R. H. Siddiqui, Nanoscale Res. Lett., 2015, 10, 52.

43 J. Chen, Y. Guo, J. Chen, L. Song and L. Chen, ChemCatChem, 2014, 6, 3174-3181. 